\title{
Pre-print
}

\author{
Protecting into emotion: therapeutic enactments \\ with military veterans transitioning back into civilian life.
}

\author{
Michael Balfour, Marv Westwood, Marla J. Buchanan
}

\begin{abstract}
Over 18.5 percent of military personnel returning from war zones to civilian life suffer mental health issues, which can lead to family breakdown, homelessness and other problems. Almost 4000 Australian soldiers have returned home from active service in the last decade suffering from combat stress and mental health conditions. A 2009 Australian independent government review warned a new generation of veterans with posttraumatic stress disorder (PTSD) and severe mental health disorders will emerge in the next five years, with as many as 1 in 4 likely to need mental health treatment.

The Difficult Return: arts-based approaches to mental health literacy and building resilience with recently returned military personnel and their families is a 3 year Australian Research Council funded arts project aimed at supporting the mental health and well being of recently returned veterans in Australia, USA and Canada. The project combines a range of arts-based strategies to help returning veterans, including online digital films to improve awareness and help seeking motivation, a performance project with ex-soldiers and actors, and a process based group work program. The paper will focus specifically on the development of the Veterans Transition Program (VTP) a partnership between Griffith University and the University of British Columbia, Vancouver. The VTP leverages the resilience and resources of veterans, providing help to participants attempting to better understand the impact of military experience on their lives. It draws on a range of psycho-educational and action-based approaches, including life review and drama enactments to engage participants in ways of dealing with disturbing events from their lives. The paper will describe and reflect on a number of the strategies used in the VTP, for example, how the drama enactments help to integrate emotion, cognition and embodied awareness, the significance of contact when working with trauma, and the importance of a therapeutic milieu in constructing 'units' of support for the veterans.
\end{abstract}




\section{Protecting into emotion: therapeutic enactments with military veterans transitioning back into civilian life.}

In the next year thousands of military personnel from the United States, United Kingdom and Australia (and other coalition forces) will return from Afghanistan and recent conflicts in Iraq. Between 18-30\% of those returning from war zones to civilian life suffer mental health issues, which can lead to family breakdown, homelessness and other problems. In the USA for example there have been 103,792 cases of posttraumatic stress disorder (PTSD) diagnosed (in the period of 2000-2012). Recent studies estimate that 1 in every 4 military personnel returning from Iraq and Afghanistan will develop some form of PTSD. Military researchers are warning that a new generation of veterans with PTSD and severe mental health disorders will emerge in the next five years (Dunt 2009). Mental health issues in the defense forces often exist within a culture of stigmatisation with servicemen often reluctant to admit to having a problem. Military personnel may not seek treatment for psychological illnesses because they fear it will harm their careers. But even among those who do seek help for PTSD or major depression, only about half receive treatment considered by researchers to be 'minimally adequate' for their illnesses.

The Difficult Return is an Australian Research Council funded project explores arts-based approaches to mental health literacy and building resilience with recently returned ex-military personnel and their families. The 3 year arts-based research project is looking at the transition from military to civilian life: awareness of psychological stress through online films on social media and embedded on relevant veteran support websites; a documentary-based performance that will engage military and non-military audiences and feature ex-soldiers as well as actors, and a group-based psycho-educational program that seeks to use action-based methods to help soldiers deal with career related stressors and the re-integration into civilian society.

In this article we focus on the Veterans Transition Program (VTP), an innovative program developed in Vancouver, Canada over the last 14 years, and brought to Australia in 2012 as part of the Difficult Return project. The program was run in both March and June of 2012 in Brisbane, Australia. Facilitated by psychologists and para-professionals (soldier-graduates of the VTP), the program draws on a variety of theoretical constructs, and includes therapeutic enactments or action based processes for helping soldier-participants revisit key moments of trauma or psychological stress. Key to the program's innovation is the integration of cognitive, affective and kinesthetic learning.

The predominant treatment ethos for veterans with PTSD is cognitive behavioural work that seeks to raise awareness of thinking skills and strategies that teach participants about the stressors, but does not actively or somatically interact with emotions or affect. Bolton's (1986) work in the area of drama and education queries the ways in which educational facilitators should guide participants from emotion or protect them into it? If ex-servicemen are numbed and/or flooded by emotion as a result of trauma or difficult returns is there a process that can help to support them in their processing of experiences and memory that is more positive? We will explore these questions in this article, through assessing the ways in which the use of enactments, or performance methodologies, in the VTP were embedded within a carefully 
constructed process that protected participants in and out of emotionally charged spaces. The paper will focus on one participant's enactment, as a way to demonstrate that the process involves a negotiation with highly emotional states, enabling the participant to, as Vygotsky (1976) described, exist in a dual affect, in which the participant was both aware of the constructed reality and simultaneously immersed in it.

\section{Coming Home}

Almost 4000 Australian soldiers have returned home from active service in the last decade suffering from combat stress and mental health conditions (Parnell, 2010). A 2009 Australian independent government review identified poor mental health literacy rates in the ADF, coupled with low help-seeking motivation, and reluctance to draw on traditional forms of support (e.g. counseling services offered by the Department of Veteran Affairs). The review identified a significant gap in the knowledge of educational interventions for veterans and their families (Dunt 2009).

In summarising the need for work in this area Westwood, McLean, Cave, Borgen and Slakov $(2010,45)$ note that:

...research shows that untreated combat trauma becomes a chronic, debilitating condition associated with a range of negative psychological, physical and social outcomes for both soldiers and their families (Rosenheck \& Fontana 1996). Summarising the need for the treatment of veterans, Ray (2006) stated, "for healing to take place, peacekeepers need to voice their grief and love not only for their dead military brothers but the loss of innocence, the loss of their band of brothers, their military family and their military careers" (p. 18). It is imperative that treatment models are developed to counteract the effects of combat-related trauma and prevent the descent of soldiers with post-traumatic stress reactions into chronic disability, unemployment and underemployment (Benotsch et al. 2003).

Early on in the ARC project the research team partnered with Professor Marvin Westwood at the University of British Columbia, who for the last 14 years had been running the Veterans Transition Program in Vancouver. The Canadian program has supported over 385 soldiers and continues providing service to approximately 15-20 veterans per year. The specific remit of The Difficult Return research aimed to observe and analyse the use of therapeutic enactments as a key element of the program, and to explore its transferability to a different cultural context.

\section{The Veterans Transition Program (VTP)}

The program is a group-based intervention that draws on group therapy, social learning, object relations, somatic theory, narrative and script-theory (Westwood, Keats and Wilensky 2002) and leverages the power of soldiers helping soldiers in providing a strength-based, non-stigmatising approach to help participants make sense of psychological stresses associated with incidents in their military career. The various elements of the VTP are conducted in a structured way to: "reduce re-activation, promote increased trust formation, and permit greater self-awareness, selfdisclosure, emotional expression and cognitive reframing" (Westwood et al. 2010, 48). Unlike other groups for trauma recovery the VTP is for veterans only. The program combines therapeutic work with micro-skills training and career development components to provide a 
comprehensive continuum that aims to support successful transition into civilian life. The VTP is a 10 day residential program, that includes five phases (Westwood and Wilensky 2005, 7):

1. Pre-Program assessment and preparation (psycho-education, teaching on PTSD and communication skills)

2. Group building (life review and communication skills)

3. Enactment

4. Sharing, reconnection, and closure

5. Post-program integration and transfer

The pre-program assessment and preparation phase involves participants meeting with a psychologist for screening and developing an understanding of individual needs. Participants can be screened out and/or referred for other appropriate forms of treatment and therapy. The screening interviews also involve a detailed explanation of the program and what is involved. Once the program commences, the focus is on a process of group building that establishes the framework of the residency, highlighting the importance of safety and inclusion, personal control, the development of trust and group cohesion. The program is residential, like a retreat, in which participants learn, practice and develop new skills and insights, Westwood (interview):

The participants work together, eat together, they share dorms that are like barracks. They have their own time and often end up talking to each other until $2 \mathrm{am}$ in the morning. Soldiers know how to help soldiers, so the program takes advantage of that. It's a rebuilding of a community.

The construction of a focused therapeutic milieu is not an accident - the program runs intensively from 9am-9pm for 10 days. Participants talk and share stories in the breaks, relax and support each other. The facilitation team also participates and many of the traditional boundaries between professional and client are broken down in terms of these social interactions, for example informal discussions, stories, jokes and support in the breaks and at meal times. This creates a real sense of shared purpose within the group. It is still clear that there is a tight structure to follow, but the group has considerable ownership over the process, and there is a strong sense of egalitarianism, the re-creating of a bond or 'mateship' rarely experienced outside of the military context. This is key as one of the difficulties with transitioning is the break from the 'family' of military ties. In their professional careers the social unit is a critical resource and is the context for dealing with combat through group rather than individual goals. In civilian contexts the treatment of psychological issues is typically individual, and/or family based, but often does not draw on or take advantage of military cultures. In the 2 programs run in Australia, this recreation of the barracks like milieu was one of the areas the participants gained a great deal from, 'it was great to be back with the boys again, in a company'. This is important too, because of the level of isolation that many of the participants are trying to manage. Rozynko and Dondershine's (1991) research highlights the value of the group approach, suggesting that it supports the development of a sense of belonging, lessens feelings of isolation, re-establishes the installation of a military-orientated group relationship again, and enables an acceptance and control of a participants' anger. As Yalom (1995) asserts, 
the group environment is a space where "the knowledge that others share similar experiences and distress, a sense of universality is helpful as clients often feel isolated, embarrassed and misunderstood prior to starting treatment." (324)

\section{Life Review}

The first major task of the program is to write about a branching point or significant turning point in their pre-military life as well as one from their professional life. The participants can do this in a variety of ways, such as bullet points, a diagram, a narrative, or detailed written description. These stories are then read into the group in a structured way, enabling the story teller to have their time, but also drawing on the other group members to actively listen and respond to the story in a non-judgemental way ("your story made me feel...; the impact of your story on me was..."). The storyteller then listens without comment to everyone's response, and then responds to everyone's comments to complete the process. Although this is a straightforward sounding process, the level of engagement is very high. In the Australian groups it was clear that this was, for some, the first time they had told their stories, or more pointedly, the first time they felt they had been listened to, without prejudice or the rush to clinical judgement.

The process of group building and life review takes 2-3 days and builds the social fabric of the program. It is clear that the linking of pre-military and career branching points can produce some interesting results for participants. The participants own self selection of stories may often suggest pre-existing conditions that have contributed to the ways in which a traumatic experience have impacted on them. And this insight is the start of a process for them to consider their identity in broader terms, to begin to understand how their current issues are shaped by more complex factors that pre-date traumas experienced in the military. Pre existing life traumas may also be identified during this process that help inform the latter trauma events experienced in their military career and presented in the group and during the enactment phase of the program.

\section{Enactments}

Westwood is clear to distinguish that the process of enactment is not about a re-enactment, re-exposure or reproducing a traumatic event, but rather creating a public ceremony that seeks to externalise and make concrete what has become an internalized script. It's a way for the member to see or look at the event from a distance. The aim of such a process is to create "an interplay between the internal world and the external here and now in public, to create an "as if" scenario that truthfully reflects the participants' present needs and awareness" (Westwood and Wilensky 2005, x). Westwood (interview):

Telling your story and enacting your story about your fears and your regrets and so on makes an internal stage external and it is then witnessed by the group and it is no longer your story - it belongs to the group and they feel relief and they feel they've dropped it and they can let go so that they can use the energy to get on with their lives.

Enactments draw on elements of psychodrama (action therapies), but with clear areas of difference from Moreno's model. There is a commonality of terminologies, for example 
enactments have protagonists, doubles, scenes, role-playing, catharsis and directors (the therapist). However, enactments are carefully constructed within a therapeutic sequence that emphasises prior screening and individual readiness and a 2-3 day group building process, before any action-based work takes place. Equally there are 2-3 days of processing, support, and re-integration or decompression elements that follow an enactment. This is an acknowledgement of the efficacy of a psycho dramatic approach, but also a recognition that individual and group safety need to be addressed to create an appropriate climate, before undertaking a potentially profound interpersonal method. There are other important divergences from Moreno, in that enactment work emphasizes the active role of the witnessing circle of the group as having as important a role to play within the individual enactment. In psychodrama the process tends to be 'protagonist focused' (Blatner 1996, 11), rather than using the group context as a way to share the trauma story leading to a greater sense of being listened to, feelings of respect and affirmation and for individuals to feel validated which is particularly important in relation to shame and guilt based stories.

Another area of divergence between psychodrama and an enactment is spontaneity. In psychodrama, the protagonist is encouraged to improvise and be spontaneous within the social interactions in the scene. In enactments, with its emphasis on safety and protecting participants into emotion, spontaneity is minimised, with the process carefully structured in advance. The scene/scenario is carefully plotted before the action takes place, away from the group, in a detailed and negotiated process between the participant and the facilitator. Key to this is the importance that the participant is not ambushed or taken by surprise in the enactment. The plotting is precise, well structured and planned. If there is a deviation from the plot, the action ceases and this is negotiated carefully. The goal here is to ensure throughout the member has a sense of personal control in the moving through the process, (e.g., stop, start, change, shift, etc.). Unusually in drama terms, the facilitator also aids the storyteller through the scene with the use of stem sentences that act as a guiding script for the participant, Kuhl (interview):

Grief and expressions of grief are quite foreign to us and especially for men, so they might not know what to say. So in the enactments we help the participant by leading with a sentence: "what I need to say to you is..." and if he doesn't know what to say we add more until he picks up on the cue. We can only do this because we know him and know the context, and we've spent a lot of time beforehand--we have a lot of understanding about what he needs to say.

The development of sentence cues is a response to the issue that participants' can lose their train of thought during enactments of difficult and traumatic events. The participants are emotionally aroused and want to say something but sometimes can't think of the exact words. So the facilitator uses the incomplete sentence to offer a cue. Sometimes the participant will complete the sentence, other times they will stop and clarify, and suggest an alternative that matches what the line should be. Typically a sentence is generic, for example, 'the thing I want to say to you is..' or 'the thing I regret most is...' or in conversation with the facilitator it is a method of clarification, 'the thing you want to say 
to your buddy is...'. The context of the scene is carefully structured as if it is an immersive video that can be stopped and started. The participant and facilitator can stop the action discuss the orientation and dimensions of the scene, before starting the action again. Critically though the facilitator has an intimate understanding of the story and what the participant needs to say or do. There is explicit discussion before and during the enactment of setting goals. What do you want to get back? What do you want to let go of? And therefore there is a clear narrative arc, almost classical in its structure, that there is a journey needing to be undertaken and there is something that they need to say or do that represent critical recovery moments. They experience a sense of personal control that is so important, as that is precisely what was lost during the traumatising event.

The obvious tension here is that a facilitator while conscious of the plot and potential script, is drawing on instinct and professional judgment that could result in over-leading a participant in a particular guided narrative. This happened on a couple of occasions in the Australian programs, but the cues are posited as questions as well as sentences, and therefore there was always room for re-appraisal and review. In some instances the participant would stop and consider, and then suggest an alternative. At other points they might check in with the facilitator to reference the direction the interaction was taking. The purpose of the sentence cues is not to make a puppet of the participant or impose a specific therapist-led therapeutic intervention, but to provide a possible script for the participant to own and express. These are core words and actions that the participant has already identified that he needs to do, and the cues provide him with the traction to find the language to fulfill the objectives of the scene or the overall goals of the enactment.

The VTP also draws concepts of body psychotherapy into the group (Knaster 1996; Levine 1997; Rosen 2003; Rothschild 2000). From the beginning of the group there is an emphasis on participants becoming more aware of how emotions impact on their physical selves, facilitators regularly check with participants, 'What are you aware of in your body right now?' and relaxation strategies are used throughout the program to increase the awareness of the relationship between mind and body. In the enactments there is considerable use between scenes or at heightened moments of emotional release to reground the participant into the here and now.

\section{The Research Approach}

Our process for analysing the enactments involved a range of measures and approaches. Standard pre-post scales of trauma, depression and anxiety were used, e.g. Beck Depression Inventory (BDI, Beck, A.T., Steer, R.A., \& Brown, G.K. 1996), participant interviews, post program follow up interviews, and the use of Interpersonal Process Recall with participants shortly after the enactment (Kagan 1984). All the enactments were filmed, and then 1-2 days after the participants would review the video session with a researcher. The participants viewed the filmed enactments in a separate room and explored significant and critical points in the enactment, and were encouraged to reflect on the meaning of their response or interaction, to recall feelings and interpret their behaviour and responses cognitively. These review sessions were also filmed for later analyses. With this approach we hoped to better understand the nature of the enactments, an examination 
of how the group process was working, and to provide participants with a deeper level of insight and reflection on their experiences.

\section{Todd's Enactment*}

I was very nervous, very apprehensive even though I'd seen 3 men in there before me and I'd seen the benefits for them. I was still apprehensive because it was going to be hard. It was going to be difficult (Interview with Todd).

The enactment took place on day 4 of the first Veterans Transition Program run in Australia in March 2012. Todd's enactment was the fourth to occur, and he had participated and observed the previous enactments. The group consisted of 2 lead psychologists Marvin Westwood (MW) and David Kuhl (DK) who facilitated, a psychologist researcher, Marla Buchanan (MB), an experienced VTP graduate student from UBC, an Australian psychologist, a researcher and a theatre researcher. There were 5 participants from a range of backgrounds and military service groups. Most had been out of the service for a number of years and had been through a number of treatment and therapeutic processes. One was considerably younger and had only recently left the services. The scenes that follow are extracts from the video of the enactment session.

The starting point of an enactment is to get the participant moving. The facilitator (MW) walked slowly with the participant (Todd) around the inside perimeter of the group. Westwood argues that the movement helps to access much more awareness of feelings, emotions and thoughts and helps to prevent freezing if the participant gets anxious. The participant first states what his goal is in doing the enactment and shares this with the group. The group is sometimes asked to reiterate or repeat the goal to make sure there is a clear sense of the purpose both for the participant and the group. This is important because the group plays an active role in stepping into parts of the story, or in being active witnesses to the process - thereby helping the member achieve his goal.

Todd was a lieutenant in a company of the Australian Defence Forces. He served in the Mechanised Infantry Battalion and Commando Battalion, and graduated from ADFA (Australian Defence Force Academy). During one of his operation he was in charge of a non-military accident that resulted in 5 fatal casualties of men under his command.

In Todd's enactment he wanted to say goodbye to his mates and 'drop some baggage, some guilt' so that 'I am not going to be a shell, I am going to be what I used to be before...'.

MW asks Todd what kind of person he was before the incident when Todd was 23. Todd responds by saying: "Confident. High resilience. Really high levels of self-esteem. I felt strong emotionally and also physically".

MW: So it would be good if you could get some of these things back, right? So is there anyone here that can stand in for you, for a few moments, a chance for you to meet yourself. 
Before the session the casting of each role has been discussed with the participant and then other group members are approached and briefed about playing a role in the enactment. Todd selects Ian to play the role of his younger self, and later one of the fatalities in the crash. Ian walks with him and Todd is asked how he feels about his younger self.

Todd: The thing I liked about you was you were strong, emotionally and physically. You were confident. You had a really high level of self-esteem, although you weren't arrogant...'

MW positions himself close to Todd, just behind his right shoulder.

MW: (to Todd) So what I intend to do today is bring you back.

Todd repeats.

MW: But before I bring you back, I have to let something go.

Todd repeats. MW asks Ian where he's been and what will happen if he can get something of himself back.

Ian [as the younger Todd responds]: I can start exploring my life again. Being in my life rather than a spectator watching it.

MW: [to Ian] I am here when you want me, but you are going to have to come and get me.

Ian repeats speaking to Todd.

MW asks Todd how he lost him. Todd retells the story of the incident to the group, providing the background, and the ways in which he felt responsibility and guilty. Todd discloses that he feels he is jinxed; that there have been 3 times when he could have been in an accident, but wasn't and other people died instead of him. The price for living is that he carries a 'shit load' of guilt. Todd is asked what he carried back from the mission:

Todd: I was focused on the fragility of life and how everything can be just snapped up and taken away in the blink of an eye.

As he passes Ian looks over to him and stops.

Todd: And I lost this part of me.

It cost me my career. My family. My life. 


\section{$[\ldots]$}

I became medically downgraded. I was taken off staff college course, which is what you have to do to become Lt. Col, which meant I'd never get promoted again.... I felt betrayed.

MW: And at home with the wife and kids?

T: ...I was very angry and very bitter. My attitude, my anger, my bitterness was transferred to my wife at the time. My wife said to me that they bore the brunt of the anger that I expressed.

MW: (pointing to Ian) If you'd been there...(Todd repeats). My kids would have had the father that they wanted...

Todd: (re-phrasing) They would have had the father that I wanted to be.

MW and Todd further clarify the details of the story, what's at stake, what's been lost, what Todd would like to get back. MW and Todd discuss how they would like to start the story. $\mathrm{C}$ was one of the fatalities and the hardest one because Todd attempted to save him but couldn't and he was also a close mate. So they agree to meet one of the other men first. The other group members take on the role of the other men involved in the accident. In each of the instances there is something important that Todd needs to say and/or hear. The role taking is honest and direct with flat almost neutral characterisation. Character accuracy is not the point, it is the words, the eye contact, the 'sense' that it is possible to reconnect with something or someone who is gone.

For example, in one of the first encounters with a comrade Todd needs to meet, Mike, one of the group members, stands up and faces Todd. At all times a facilitator stands close, often in contact with Todd. The co facilitator, David Kuhl (DK), stands behind the other 'actor'. Often there is a direct contact (e.g., hand on one's shoulder, or back) that is significant as a support and a literal back up. The facilitators stand slightly behind and feed in the sentence cues, observing the action, and making assessments about what the core script needs to be.

MW: So what I need to say to you is...

Todd repeats. Pauses.

MW: I am carrying the guilt of your death.

Todd repeats and then talks about their relationship, sometimes difficult, but one that was evolving into a stronger connection and trust.

MW: What I regret most is... 
Todd: (repeats) Not having the opportunity to tell you that...I regret not being able to say goodbye.

MW: But I am doing that now...

Todd repeats.

MW: ... and as I do that now (Todd repeats) ... and tell my truth (Todd repeats) . . I am beginning to (Todd repeats)

Todd: Beginning to feel lighter.

MW: I needed to say that to you (Todd repeats) because I was starting to care about you (Todd repeats) and I didn't want you to die (Todd repeats) carrying that resentment (Todd repeats).

$[\ldots]$

MW: I need to let you go. (Todd repeats). And all I need to say is that I am sorry that I didn't get to talk to you (Todd repeats).

Todd: (repeats and adds): ....and express how I feel.

MW: Can you let me go?

Todd (to Mike) Can you let me go?

DK (whispering to Mike) I can let you go (Mike repeats).

DK (to Mike): I have the same regrets as you (Mike repeats). And it wasn't your fault that I died (Mike repeats).

At this point Todd, holding Mike's hand releases tears. He covers his face with his hands. MW grips his shoulder, giving him permission to let the emotion go. MW asks him to be aware of his body. Asks him if he is aware of his body and that he has let something go.

A pause.

DK (to Mike): I need you to carry on with the work that you are going to do. I know that you can do that. Will you do that for me (Mike repeats)?

MW asks Todd if he could repeat what he heard.

Todd: He asked me to move on with my life and do the work I need to do.

MW: I regret that I had to be there... and why I stayed was... 
T: It was hard to stay but I stayed there to look after you [in the morgue]. I didn't want you to be alone. I wanted your family to know that there was someone there with you. That you didn't die by yourself. I felt that I was protecting you and that I was very proud that I could do that.

MW: Now I can let you go.

Todd repeats.

Mike sits down. MW and Todd start walking again. They reflect as they walk. MW checks in with Todd and ask him of what he is aware of in his body.

$[\ldots]$

Todd: As soon as he said that it wasn't my fault, I didn't feel as responsible.

MW asks him to reflect on how he is walking. Todd feels lighter, a little less weight. Todd discusses what scene might come next. MW reminds him of his support in the room. MW and Todd discuss the next scene.

In the final meeting with his comrades, Todd describes his friend who died in the crash, his sense of humour, his intelligence and liveliness. They establish the details of the accident, where the friend was, where Todd was. MW asks him to describe what he saw when he arrived at the accident scene. How he was feeling. What he saw. They establish the setting, moving aside chairs, to create a representative space. MW and Todd continue to walk round the circle. This is a key scene so the details are explored minutely. They come to the point where Todd gets to his friend who is lying on the ground. Todd chooses Ian (the same person who played his younger self) to play the friend. Ian gets into position, as directed by Todd, MW asks Todd to explain to the group what he is doing.

Todd: (is kneeling by his friend with a medical kit) It's all muddy here, and there is blood. I have to do CPR and before my mind knows what it is doing my hands are finding the area. And then I start the compressions...

Todd continues with the description, enacting what he did. Putting his hands together to do the compressions on his friend. Todd is very factual, forensic, in what is happening.

Todd: ... he is unconscious. We were barely keeping him alive.

MW: So pause now, and say. As I revisit this I am aware...

Todd: I am aware that he is barely alive.

MW: And I am feeling helpless... 
Todd repeats.

MW: because every time...

T: Every time I try to push life into him...

MW: I maybe pushing him closer to death...

Todd repeats.

$[\ldots]$

DK comes to kneel down beside Todd and asks him to re-take up the position of the compression moves on his chest.

DK (to Todd): I realise that as I work with him (T. repeats). His life is slipping away (T. repeats). He is dying (Todd repeats). Under my hands (T. repeats). And before my eyes (T. repeats). I have a sense of helplessness (T. repeats), hopelessness ( $T$. repeats) despair (T. repeats) and dread (T. repeats). (Beat).

Todd starts to release emotion.

DK: (to Todd): I am doing my best (T. repeats). But it cannot save his life (T. repeats).

$[\ldots]$

MW (to Todd): As you sit here now with us, what are you aware of in your body right now?

T.: It's very tense.

$[\ldots]$

MW: I think you might want to say something to him now, something you didn't say before he died.

$[\ldots]$

MW: He's going to die but he's alive for a little while. His eyes are open.

Ian opens his eyes. Todd takes Ian's hand and grasps it.

MW: This time has been a long time coming, hasn't it? So, I need to say to you... 
T: I need to say to you (beat). I am sorry that you are passing (beat). I am sorry that you die.

MW: And the reason I am so sorry ...

T: And the reason I am so sorry (beat) is that I feel like I failed you. And that I couldn't help you. And I couldn't save you...(becoming emotional).

DK: (to Todd): And I can't let go off that.

T: Because I can't let go off that.

$[\ldots]$

MW sits behind Todd, leaning into him up as he sits on the floor grasping Ian's hand, a literal and figurative support. DK has moved close to Ian and as the scene progresses, Ian (as his friend) has the opportunity to respond.

DK (to Ian): I was bleeding so fast nothing could have stopped it (Ian repeats). There was nothing you could do (Ian repeats). I want you to hear that (Ian repeats).<smiles></smiles>

DK (to Ian): You stayed with me. I felt your hand (Ian repeats).

$[\ldots]$

Todd: I was there when they conducted an autopsy on you. And I wanted to do it so your family knew you were not alone.

MW: And I did that for you.

Todd: And I did that for you.

The scene continues as Todd and MW work together to make sure everything important is said. MW reminds him that soon he will have to say goodbye to his friend and the other men. The other actors come in from the circle and lie down as the dead men. Todd covers each with a blanket and says to them one thing he will take from them. He takes the time to say goodbye the 'right way'. The 5 bodies lie beside each other on the floor. Todd takes care with each person, making sure the blankets cover the entire body. He says goodbye, and then lifts the blanket over their faces. There is a sense of honouring and carefulness to these actions. Todd puts his hand on each actor, and says goodbye.

Todd (to Ian): Goodbye. I leave you to the last because for all these years I felt that I failed you, and that I should have done more to try and save you. 
MW: But as I realise now about what I have said . . (Todd repeats). I don't need to carry you (Todd repeats).

DK: And today I realise (Todd repeats). That there was no-one that could have saved you (Todd repeats). And I know it wasn't my fault (Todd repeats). So I will go on living (Todd repeats). I am going to cover you up (Todd repeats). And I am going to walk out of the room (Todd repeats). And I am going to walk into the rest of my life (Todd repeats).

Todd: Before I go I want you to know that I will take with me your creativity. Goodbye.

They stand up and say a final good-bye and DK and Todd walk out leaving the covered bodies in the room.

\section{$\underline{\text { Discussion }}$}

The VTP provides an example of possible strategies for supporting veterans and exservicemen with combat and/or career related stress issues. The program, in line with current best practice in the trauma literature (Ruzek et al. 2001; Solomon and Johnson 2002), integrates cognitive and behavioural methods with measured action-based exposure type techniques. Equally it seeks to integrate posttraumatic stress issues with posttraumatic growth. If posttraumatic growth is to occur then safe, exposure-type techniques that protect participants into emotion are important. The enactments described in this article demonstrate strong links to psychodrama, but importantly there are strong elements of containment or protecting participants into (and out of) emotion that are rare in the field of psychodrama or drama therapies, where there is less time in preparing, containment and follow up. Therefore, the conditions of care surrounding the use of enactment as a measured exposure technique, exist on at least two levels, the structural level of the program (10 days of intensive work that lead into enactment and away from it), a process of carefully scaffolding a depth and breadth of engagement with interpersonal issues and second the enactment process itself. As Todd's case study illustrates, there are a number of protective factors involved within the enactment:

- Preparation pre-plotting, collaboration and pre-scripting.

Counter to psychodrama where spontaneity is valued, the purpose of the enactment might lead to spontaneity, but within the process there is a clear structure. Furthermore the story, its content, its treatment are discussed in detail in advance of the scene with the participant. This is important, as the participant needs the time to reflect, discuss and select what he feels is the most important story, as well as one he feels he is able to undertake. Considerable clarification and collaboration is undertaken, before the enactment is due. Once the story has been selected, the participant elects group members to take on certain roles, and they are approached, again in advance.

- The dual affect.

A common drama and/or psychodrama technique of distancing is used in the enactment. The participant is both aware of the constructed reality and simultaneously immersed in it. 
Todd noted about his experience:

It's really hard to describe. Even though the rational part of your brain says it is not really them, there is a part of you that thinks it is and you really are back there and they now alive and talking to you. It's incredibly powerful.

The facilitator uses the dual affect to enable a standing back from the action. Sometimes, enabling the participant to view the action through use of a double, at other times being placed within the action. The dual affect also constructs different notions of time. For example starting and finishing in the here and now, and between scenes the facilitator might ask the participant to reflect on the scene, or ask the group for their observations, or simply look round the group and name them as supportive witnesses in the process. The participant can then re-enter the past memory again in the knowledge that it is possible to create distance and not threaten to overwhelm. This acts as a grounding mechanism, a way to review and reflect in-action. It acts to pause or bracket the intensity of the scenes.

- Strong narrative arc, driven by clear goals and objectives.

The preparation of the scene in advance, gives the participant a clear sense of what will happen in the enactment. Todd was asked what he was going to let go of, what ways his life might be better. Part of this process was identifying and embodying his younger self, what he once was, and what had been lost. This is both a literal and symbolic figure. The goal or super objective of the enactment is to get back himself, his family, his life. Within the scenes with his dead comrades, are unit objectives, specific things that need to be said to specific people. The structure provides a secure pathway through the process, it implies safety, but is nevertheless fraught. The 'dangers' exist, but they are approached methodically, and with care, and negotiation. A further protective factor is the combination of preparation, negotiation, setting goals and a strong narrative arc. The participants must feel that the process is secure and worthwhile there must be trust in the process.

- Sentence cues as containment and support

One of the potentially contentious techniques used in the process of the enactment is the use of sentence cues. Viewed externally, facilitators may look like puppeteers imposing words and thoughts through the participant. The facilitator says a stem sentence, the participant repeats the sentence, and then if they are clear completes it with his own words. Westwood's (interview) rationale for the development of this technique is that:

When people are in the middle of reenacting a very stressful event their thoughts aren't very clear, they have a lot of emotion and they know whey want to say something but they can't think of the words. But we know from our own research that certain things have to be said at certain at certain critical recovery moments that are very simple and straightforward and they have to say it. It is a form of using language to complete or close a 'gestalt' that previously was fractured or incomplete. 
The effectiveness of sentence cues rests in the preparatory stages with the participant and the experience and expertise of the facilitator in understanding the core script at the heart of the scene. During any enactment there is subtle negotiation. At times the participant repeats entire sentences provided by the facilitator, at other times he can complete the sentence. There are also numerous occasions in most enactments when participants rephrase sentences provided by the facilitator, or pause, check with the facilitator and re calibrates the message entirely. When scenes are flowing, there can be an interchange where both facilitator and participant are starting and finishing sentences mutually. But more often than not the experience is overwhelming and the flooding of emotions constricts language. The sentence cues create a degree of ceremony also, the respectful oath, the emphasis on non-naturalistic forms of communication. The exchanges in enactments are hyper-realistic, essentialist in value. These are words that have to be said that break the coda of everyday communication, to what lies beneath the surface. They connect strongly with the super objective of the enactment, and the unit objective of the scene.

- Reflection in and on action

The preliminary program stages train the group members to reflect and connect experiences with themselves. The life review process equips the group to reflect and connect with others stories in direct and supportive ways. This growing faculty for structured reflection is a powerful protective factor in de-briefing with the participant after the enactment. Typically a participant can be quite disorientated and this gives the group the opportunity to reflect on how the enactment story has impacted on them. This can often take as long as the enactment, and has the effect of calming the participant, and offers a way of seeing how his story of shame and/or guilt that has forced him into isolation, is in fact shared and ricochet's around the groups own personal lives. The reflective process universalises a very specific, personal story - in effect 're-storying' this part of their life. After the group has reflected, the participant then acknowledges the groups' responses and reflects on his experience of the enactment. The following day there is further time for reflection, as often the participant has had a dream and/or a wakeful and disturbed night, and wants to share the ways in which he is beginning to integrate and make sense of the experience. Again this time is valuable and key to processing and learning from the enactment. The added reflective element in the Australian VTP was the use of video process recall, that while intentioned as a research mechanism, actually became an added layering of reflection on action, as the participant viewed the video of the enactment, and responded to questions about their experience. This in fact is now being recommended as a central technique of the process in the Canadian program.

- Group witnessing - servicemen helping servicemen.

One of the final layers of protection is the way in which the program is veteran-based and not a combined civilian group. The impact of this within the general process, but the enactment process specifically, is that there is a very strong common bond (and some competition) between people who have served. It comes from a shared culture, a shared understanding of technical knowledge, and a common understanding that is instinctive. A high level of trust and complicité is established early on in the program because the 
veterans are more ready to trust others 'who have been there'. Therefore in the enactment, this bond provides an efficacious witnessing and validation of a trauma story. The bond demands honesty, but provokes a unitary response of almost absolute support, that connects back to the need for entrusting individual life to the responsibility of the military unit/group. It is palpably different from a civilian group, and the program utilises this to construct a positive process of repair and attention to war-related trauma.

\section{$\underline{\text { Implications }}$}

I am certainly not the man that I used to be but I don't seem to have that tension and stress that used to bottle me up. I've had a huge release of emotion so that's not bottled up inside me either. I know I am not out of the woods yet. There is still a long way to go but I've been given a bit more hope and a lot more optimism. Optimism about the future so I am now keen to move forward and get on with my life (Interview with Todd).

Many of the Australian VTP participants were infused with considerable confidence and optimism after the program. The goal-setting phase of the program orientates them to being realistic that it is not all over and they can 'come of their meds'. There is a careful process of protecting participants back into their lives. The 10 days have been like a retreat, and considerable time is taken in planning how to integrate their experience back into everyday life. Expectations that things might get worse before they get better are discussed. What support structures are in place, e.g. families, counselors, psychologists and psychiatrists. In both programs formal follow up with the Australian psychologist was conducted, as well as post program interviews. One of the most enduring supports has been the group members' formally and informally maintaining contact with each other. Helping each other out in the follow up period as well as staying in touch with the research team.

One of the aspects that participants suggested could be improved was greater inclusion and involvement with families and friends, during all aspects of the process. And this is something that will be addressed, more likely in the Canadian program, as there are no definite plans to repeat the Australian program until the evaluation and research has concluded.

What the research has offered us though, is the opportunity to understand and value the ways in which performance processes can safely enable veterans and ex-serviceman dealing with trauma and career-related stress to confront and process their feelings of helplessness, providing them with a different relationship with the traumatic event. Regardless of the politics of recent wars, the next few years will witness the large-scale return of thousands of servicemen from Afghanistan and Iraq, some of whom will be profoundly impacted by the experiences they have had, and who will have to make the treacherous mental and emotional journey home.

Notes

*Following ethical procedure, all participant names have been changed. However Todd has formally requested that his name be kept as it is. 


\section{References}

Balfour, M. 2010. The Difficult Return: Contexts and Developments in Drama-Based Work with Returned Military Personnel. Applied Theatre Researcher 10.

Beck, A.T., Steer, R.A., \& Brown, G.K. 1996. Manual for the Beck Depression InventoryII. San Antonio. TX: Psychological Corporation.

Benotsch, E. G., Brailey, K., Vasterling, J. J., Uddo, M., Constans, J. I., \& Sutker, P. 2000. War zone stress, personal and environmental resources and PTSD symptoms in Gulf War veterans: A longitudinal perspective. Journal of Abnormal Psychology 109: 205-213. Blatner, A. 1996. Acting-In: Practical Applications of Psychodramatic Methods. 3rd Edition. New York: Springer.

Bolton, G. 1986. Emotion in the dramatic process-Is it an adjective or a verb? In D. Lawrence Eds., Gavin Bolton: Selected writings: 100-107. London: Longman.

Davis, C., Kagan, Norman; Krathwohl, David R.; Miller, Ralph. 1963. Stimulated recall in therapy using video tape: A case study. Journal of Counseling Psychology Vol 103: 237-243. doi: $10.1037 / \mathrm{h} 0045497$

Dunt, D. 2009 Review of Mental Health Care in the ADF and Transition through Discharge. Department of Defence, Australian Government.

Han K. Kang, Dr.P.H., and Kenneth C. Hyams, M.D., M.P.H. 2005. Mental Health Care Needs among Recent War Veterans. New England Journal of Medicine, 352: March 31, DOI: $10.1056 / \mathrm{NEJMp} 058024$

Hoge , C.W., Auchterlonie, J.L., Milliken, C.S. 2006. Mental Health Problems, Use of Mental Health Services, and Attrition From Military Service After Returning From Deployment to Iraq or Afghanistan. Journal of the American Medical Association, 295 9: 1023-1032.

Kagan, N. 1984. Interpersonal process recall: Basic methods and recent research. In D. Larson Ed., Teaching psychological skills: Models for giving psychology away: 229-244. Monterey, CA: Brooks/Cole.

Knaster, Mirka. 1996. Discovery the Body's Wisdom. New York: Bantam Books. Levine, Peter, A. with Ann Frederick. 1997. Waking the Tiger: Healing Trauma. Berkely, CA: North Atlantic Books.

Parnell, S. 2010. 4000 Diggers on war sick list The Australian. 20/1/2010: 1

Payne, Alexandra J., Joseph, Stephen \& Tudway, Jeremy. 2007. Assimilation and Accommodation Processes Following Traumatic Experiences. Journal of Loss and Trauma: International Perspectives on Stress \& Coping 12:1: 75-91.

Ray, S. L. 2006. Embodiment and embodied engagement: Central concerns for the nursing care of contemporary peacekeepers suffering from psychological trauma. Perspectives in Psychiatric Care 42: 106-113.

Rosen, Marion with Brenner, Susan. 2003. Rosen Method Bodywork: Accessing the unconscious through touch, Berkely, CA: North Atlantic Books.

Rothschild, Babette. 2000. The Body Remembers: The Psychophysiology of Trauma and Trauma Treatment, New York: W.W. Norton and Co.

Rozynko, V., \& Dondershine, H. E. 1991. Trauma focus group therapy for Vietnam veterans with PTSD. Psychotherapy, 28: 157-161. 
Rosenheck, R., \& Fontana, A. 1996. Treatment of veterans severely impaired by posttraumatic stress disorder. In R. J. Ursano \& A. E. Norwood Eds., Emotional aftermath of the Persian Gulf War: Veterans, families, communities, and nations: 43-70.

Washington, DC: American Psychiatric Press.

Vygotsky, L. S. 1976. Play and its role in the development of the child. In J. S. Bruner, A. Jolly, \& K. Sylva Eds., Play-Its role in the development of evolution: 537-554. Middlesex: Penguin Books.

Westwood, M.J. \& Wilensky, P. 2005. Therapeutic enactment: Restoring vitality through trauma repair in groups. Vancouver, Group Action Press.

Westwood, M. J., McLean, H., Cave, D., Borgen, W., \& Slakov, P. 2010. Coming Home: A Group-Based Approach for Assisting Military Veterans in Transition. The Journal for Specialists in Group Work 351: 44-68. doi:10.1080/01933920903466059

Yalom, I. D. 1995. The theory and practice of group psychotherapy. New York, NY: Basic Books 